\title{
Presentación del debate: Historias que no quieren ser contadas. La representación de la violencia estatal en los museos de las Fuerzas Armadas y de seguridad
}

\section{Mariana Sirimarco}

\section{(2) OpenEdition}

\section{Journals}

Electronic version

URL: http://journals.openedition.org/corpusarchivos/3413

DOI: 10.4000/corpusarchivos.3413

ISSN: 1853-8037

\section{Publisher}

Diego Escolar

\section{Electronic reference}

Mariana Sirimarco, « Presentación del debate: Historias que no quieren ser contadas. La

representación de la violencia estatal en los museos de las Fuerzas Armadas y de seguridad », Corpus

[En línea], Vol. 10, No. 1 | 2020, Publicado el 28 junio 2020, consultado el 02 julio 2020. URL : http:// journals.openedition.org/corpusarchivos/3413; DOI : https://doi.org/10.4000/corpusarchivos.3413

This text was automatically generated on 2 July 2020.

Licencia Creative Commons: Atribución-NoComercial 2.5 Argentina (CC BY-NC 2.5 AR) 


\title{
Presentación del debate: Historias que no quieren ser contadas. La representación de la violencia estatal en los museos de las Fuerzas Armadas y de seguridad
}

\author{
Mariana Sirimarco
}

1 El corpus de investigaciones locales sobre las Fuerzas Armadas y de seguridad ha fatigado escuelas, predios, oficinas, dependencias, bibliotecas y archivos, pero poco $\mathrm{y}$ nada se ha metido con sus museos. El hecho no deja de llamar la atención, si consideramos que parece no haber fuerza nacional que no los posea, y si consideramos, sobre todo, que se trata de ámbitos inigualables para dar cuenta de lógicas y relatos institucionales. Así y todo, su posición dentro de los análisis de estas agencias no ha logrado superar la cualidad de lo curioso o lo accesorio. Su papel como objeto de estudio en sí mismo se ha mantenido largo tiempo por debajo del radar de los cientistas sociales (Sirimarco, 2019). ${ }^{1}$

2 Este debate intenta abordar estos espacios, partiendo de una premisa particular: la de que todo museo es, por definición, un dispositivo paradójico, orientado a hacer que una reunión de elementos heterogéneos se vuelva una representación -al tiempo que una explicación- de una cierta porción del mundo. Des-contextualizando y recontextualizando objetos, un museo es un artefacto que logra crear, a través de voces fracturadas, una narrativa común (Donato, 1979; Sherman, 1995; Escobar, 2010).

3 Los museos de las Fuerzas Armadas y de seguridad no escapan a esta lógica. Presentados en tanto espacios de conservación histórica, tal cariz revela, sin embargo, una de las formas clásicas que toma la ficción gobernadora de un museo. Pues todo museo es, antes que un espacio de exhibición del pasado, un sitio de memoria disputada. Es decir, un dispositivo que elige, ordena y clasifica, pero no para representar el espectro histórico, sino para modelarlo. o lo que es lo mismo, para 
proponer una vinculación con la memoria que es estratégica y contingente. Como señalan numerosos autores, no hay nada más lejano a la idea de museo que el sentido de un pasado estático e inerte, de un pasado "muerto". Un museo es siempre, por el contrario, una superficie de confrontación (Donato, 1979; Sherman, 1995; Buffington, 2012; Tello, 2012).

Este debate busca pensar a los museos locales de las Fuerzas Armadas y de seguridad desde esta perspectiva, entendiéndolos como espacios que operan políticamente sobre la reconstrucción del pasado. Y busca desandar este eje a partir de echar luz sobre una cuestión que, en estos museos, suele quedar por fuera de cualquier guión curatorial. Me refiero a la violencia estatal y sus representaciones. Sabido es que el papel que han jugado estas fuerzas en el contexto nacional las ha llevado a desplegar un extenso accionar represivo sobre distintos grupos sociales a lo largo de la historia (indígenas, criminales, bandidos, delincuentes, vagos/desocupados, inmigrantes, pobres, militantes políticos, trabajadores populares, subversivos, etc.). Sin embargo, la elusión de estas prácticas y de estos pasajes de su historia institucional es un denominador mayormente común en estos museos. Se trata de huecos, olvidos y silencios que aparecen, aquí y allá, en la trama con que se tejen los relatos de sus accionares (Escolar, 2005, 2017, 2019; Da Silva Catela, 2011). Pero no debe creerse que sean estas omisiones puntos sueltos o corridos -errores visibles que desmerecen el paño-; se trata más bien, creo yo, de elusiones vitales que permiten mantener pareja y unida la trama. De ausencias de algún modo necesarias para no tensionar el hilado de la memoria institucional y de las identidades colectivas.

5 Este debate se propone indagar entonces en torno a estas zonas brumosas: ¿cómo pensar lo que estos museos muestran? Pero, sobre todo, ¿cómo pensar lo que soslayan? ¿Cómo se representan, en ellos, esas historias que no quieren ser contadas? ¿A partir de qué elementos y de qué relatos? Si acordamos que también la omisión de una narrativa construye memoria, las preguntas se profundizan: ¿cómo perseguir, en definitiva, el rastro de esa ausencia; cómo disputar la memoria de una violencia estatal que no se nombra?

Plantear estas preguntas implica asumir que las operaciones sobre la memoria entrañan mecanismos tan complejos como variados a la hora de abordar ciertos silencios. Existen, por supuesto, los vacíos narrativos y los objetos que no se muestran: hechos, prácticas (y responsabilidades) borrados de un plumazo de la historización institucional, tal como solían limpiarse las inscripciones que los secuestrados habían dejado en las paredes de los centros clandestinos de detención durante la última dictadura cívico-militar. Existe también la sanitización de lo que sí se exhibe, con elementos presentados de tal modo que logran revertir su carga incómoda: vitrinas repletas de armas, por ejemplo, que nos hacen olvidar, con su profusión de información técnica, su vinculación con la comisión o la represión de delitos. Y existen además materiales colaterales, que guardan huella tangencial de aquello que no se nombra (Jones, 1996; Scott, 2015; Rufer, 2018). ¿Qué presencia -directa, negada, esterilizada, oblicua- existe de la violencia estatal en los museos referidos? ¿Cómo va moldeándose esta presencia al vaivén de tiempos, contextos, agencias y actores, que corren tanto por dentro como por fuera de las fuerzas mencionadas?

7 Este debate busca orientarse en torno a tales preguntas, para establecer algunos puntos de discusión alrededor de los modos en que las fuerzas armadas y de seguridad representan, en espacios de exhibición pública, la violencia estatal que los tuvo como 
protagonistas. Las contribuciones que se presentan no pretenden agotar la totalidad de los espacios ni de los objetos museísticos: proponen, sí, recorridos orientadores para moverse a lo largo de instituciones y materialidades diversas. El resultado es un escenario de amplitud, que no solo cruza agencias estatales y exhibiciones, sino que lo hace apostando también al cruce de tiempos históricos y miradas disciplinares.

Así, José Garriga Zucal explora el Museo Policial de la Policía de la Provincia de Buenos Aires, interrogándose acerca de la construcción de una imagen policial sin máculas a través de una preocupación doble y anudada: ¿qué figuras históricas se sacan, para ello, de la vista? ¿Cuáles se ofrecen, por el contrario, magnificadas y en primer plano, para ser convertidas en héroes? Carlos Masotta recorre, a su vez, el Museo Histórico de la Gendarmería Nacional Argentina, reponiendo eventos y fragmentos de memoria para dejar al descubierto el proceso mediante el cual el ejercicio de la violencia sobre las poblaciones indígenas termina trocándose en un exhibicionismo sacro y honorífico. Martín Albornoz propone, en el Museo de la Policía Federal Argentina, una mirada capaz de horadar la funcionalidad de un acervo antiguo, caótico, profuso y disperso, para revertir, de la mano de algunas figuras -el jefe Federico Foppiano, el comisario Evaristo Meneses, el anarquista Severino Di Giovanni-, el relato aplanado de la inmersión policial en la violencia política. Diego Nemec y Santiago Garaño amplían la escala de lo material observable: ya no objetos sino pueblos (fundados por el Ejército Argentino durante los inicios de la última dictadura en el sudoeste tucumano); esto es, museos a cielo abierto construidos para producir, arquitectónica y por ello experiencialmente, la memoria oficial del Operativo Independencia. Mariana Sirimarco pone bajo la lupa los documentos de identidad y las ropas exhibidas en una sala de un cuartel cordobés en 1977, en pleno terrorismo de Estado, preguntándose por los procesos de enmascaramiento de la violencia que fueron necesarios para la exposición pública y legítima de tales materiales; preguntándose también, finalmente, si toda violencia es sanitizable. Y porque la pregunta por estas fuerzas no se restringe a una definición cerrada, María José Sarrabayrouse Oliveira inspecciona, finalmente, un espacio que las complementa, el Museo Forense de la Morgue Judicial, para reflexionar -a través de un busto, un expediente y una vértebra- acerca de la violencia ejercida por la medicina y las burocracias judiciales/policiales, a comienzos del siglo XX, sobre los cuerpos de las poblaciones pobres.

9 Este debate entraña, como se ve, un desafío particular. El de trabajar con materialidades. Es decir, el de proponerse pensar a través de las cosas. Y añado: el de proponerse pensar más allá de su realidad evidente. Pues aun cuando estos objetos se presenten como "elocuentes" -capaces de comunicar su propia significación visualmente, en cualquier marco contextual que el museo les asigne-, se trata en realidad de instancias elusivas (Sherman, 1995; Heumann Gurian, 2001). Un objeto no es nunca una cosa dada de antemano, algo que porta verdad de por sí, sino un espacio de relaciones sociales y sujeto, por lo tanto, a multiplicidad de ordenamientos e intervenciones.

10 Sobre este reto se monta este debate. Y sobre otro añadido: el de establecer un diálogo o, en todo caso, una escucha activa; una capaz de confrontar lo que estos espacios museísticos tienen de hecho para decir con relación a cómo se construye el entendimiento de la represión y la violencia (si es que se trata de lo mismo) cuando se ejerce desde el Estado. 


\section{BIBLIOGRAPHY}

Buffington, R. (2012). Institutional memories. The curious genesis of Mexican police museum. Radical History Review, 113, 155-169.

Caimari, L. (2012). Vestiges of a hidden life. A visit to the Buenos Aires Police Museum. Radical History Review, 113, 143-154.

Donato, E. (1979). The museum's furnace: notes towards a contextual reading of Bouvard and Pécuchet. En J. Harari (Ed.), Textual strategies. Perspectives in post-structuralist criticism, (pp. 213-238). Ithaca: Cornell University Press.

Da Silva Catela, L. (2011). Pasados en conflictos. De memorias dominantes, subterráneas y denegadas. En E. Bohoslavsky, M. Franco y M. Iglesias (Comps.), Problemas de Historia Reciente del Cono Sur, (pp. 99-124). Buenos Aires: Prometeo Libros/UNGS.

Escobar, T. (2010). Los desafíos del museo. El caso del Museo del Barro (Paraguay). En A. Castilla (Comp.), El museo en escena. Política y cultura en América Latina, (pp. 167-183). Buenos Aires: Paidós.

Escolar, D. (2005). Represión y Represión. Memorias, política militar y estrategias institucionales en la Gendarmería Nacional Argentina. En E. Herschberg y F. Agüero (Comps.), Memorias militares sobre la represión en el Cono Sur. Visiones en disputa entre dictadura y democracia (pp. 143-174). Madrid y Buenos Aires: Siglo XXI.

Escolar, D. (2017). Gendarmería: Los límites de la obediencia. Buenos Aires: Editorial SB.

Escolar, D. (2019). El museo del olvido: apuntes sobre la reconstrucción de la imagen institucional de la Gendarmería Nacional Argentina, 2001-201. En M. Sirimarco (Org.), Narrar el oficio. Los museos de las fuerzas de seguridad como espacios de ficciones fundadoras, (pp. 139-162). Buenos Aires: Editorial Biblos.

Heumann Guarian, E. (2001). What is the object of this exercise? A meandering exploration of the many meanings of objects in museums. Humanities Research, 8, 25-36.

Jones, S. (1996). Making histories of wars. En G. Kavanagh (Ed.), Making Histories in Museums, (pp. 152-163). Leicester: Leicester University Press.

C2020-06-23T13:24:00CRinesi, E. (2017). Puchos y cucarachas. El estatuto de lo residual en la subjetividad y la política. Psicoanálisis en la Universidad, 1, 119-131.

Rinesi, E. (2019). Restos y desechos. El estatuto de lo residual en la política. Buenos Aires: Caterva Editorial.

Rufer, M. (2018). La memoria como profanación y como pérdida: comunidad, patrimonio y museos en contextos poscoloniales. A Contracorriente: una revista de estudios latinoamericanos, 15(2), 149-166.

Scott, J. (2015). Objects and the representation of war in military museums. Museum \& Society, 4 , 489-502.

Sherman, D. (1995). Objects of memory: history and narrative in French war museums. Society for French Historical Studies. 1, 49-74.

Sirimarco, M. (2014). La cosa y la palabra. Relato y emocionalidad en un museo policial. Revista del Museo de Antropología, 7, 177-188. 
Sirimarco, M. (2019). Presentación. Museos y fuerzas de seguridad en la Argentina. En M. Sirimarco (coord.), Narrar el oficio. Los museos de las fuerzas de seguridad como espacios de ficciones fundadoras (pp. 9-30). Buenos Aires: Editorial Biblos.

Tello, M. (2012). (Sobre)vidas: objetos, memorias e identidades en la transmisión de experiencias concentracionarias. Revista del Museo de Antropología, 5, 141-148.

\section{NOTES}

1. Para ciertas contribuciones tempranas en el ámbito local, ver Caimari (2012), Sirimarco (2014).

\section{AUTHOR}

\section{MARIANA SIRIMARCO}

Facultad de Filosofía y Letras, Universidad de Buenos Aires y Consejo Nacional de Investigaciones Científicas y Técnicas, Argentina.

Correo electrónico: maikenas@yahoo.com.ar 